\title{
Review of mass transfer aspects for biological gas treatment
}

\author{
Norbertus J. R. Kraakman • Jose Rocha-Rios • \\ Mark C. M. van Loosdrecht
}

Received: 15 March 2011 / Revised: 30 April 2011 / Accepted: 1 May 2011 / Published online: 24 June 2011

(C) The Author(s) 2011. This article is published with open access at Springerlink.com

\begin{abstract}
This contribution reviews the mass transfer aspects of biotechnological processes for gas treatment, with an emphasis on the underlying principles and technical feasible methods for mass transfer enhancements. Understanding of the mass transfer behavior in bioreactors for gas treatment will result in improved reactor designs, reactor operation, and modeling tools, which are important to maximize efficiency and minimize costs. Various methods are discussed that show the potential for a more effective treatment of compounds with poor water solubility.
\end{abstract}

Keywords Mass transfer limitation · Bioavailability. Biofiltration $\cdot$ Biotrickling filters $\cdot$ Biofilters $\cdot$ Partitioning bioreactor Capillary channels $\cdot$ Taylor flow

\section{Introduction}

Biological gas treatment can be defined as the transformation of gaseous compounds to less harmful or more valuable products through the action of microorganisms. The treatment of gases using biological methods is rapidly gaining acceptance as a sustainable alternative to more conventional techniques such as chemical scrubbing,

N. J. R. Kraakman $(\bowtie) \cdot$ M. C. M. van Loosdrecht

Laboratory of Biotechnology, Faculty of Applied Sciences,

Delft University of Technology,

Julianalaan 67 ,

2628 BC Delft, The Netherlands

e-mail: n.j.r.kraakman@tudelft.nl

J. Rocha-Rios

Departamento de Ingeniería de Procesos e Hidráulica (IPH),

Universidad Autónoma Metropolitana-Iztapalapa,

Av. San Rafael Atlixco No. 186,

09340, México, DF, México incineration, and adsorption where a pollutant is only transferred from the gas to other phase (adsorption) or where toxic by-products can be generated (chemical scrubbing and incineration). Biological gas treatment is accepted as an economical and reliable air pollution control technology for treating gases with relatively low concentrations of pollutants (Kennes and Veiga 2001; Groenestijn and van Kraakman 2005; Shareefden and Singh 2005; Estrada et al. 2011). The growing emphasis on sustainability will even more stimulate the application of biological processes for gas treatment.

The reactor lay-out of a biological gas treatment system is generally relatively simple, but the process of biological gas treatment involves a series of complex physical, chemical, and biological processes. Many of these fundamental processes in biological gas treatment systems like mass transfer still require research (Popat and Deshusses 2010). As a result, biological gas treatment systems are often built and operated without knowledge of the rate-limiting steps in the system (often resulting in scale-up problems) and design and operations are mainly based on empirical experience.

The different biological techniques are traditionally classified in biofilters, biotrickling filters, and bioscrubbers. This classification has been enriched with different new configurations for biological gas treatment such as rotating bioreactor contactors, moving bed trickling filters, membrane bioreactors, bubble-tank bioreactors, airlift bioreactors, monolith bioreactors, twophase partitioning bioreactors, fungal biofilter, and mist bioreactors (Kennes and Veiga 2001 and Shareefden and Singh 2005). This diversification of the technology requires the knowledge of the rate-limiting steps in these systems in order to design, scale-up, and operate the most suitable system for a specific application.

Typically, a bioreactor for gas treatment is operating under mass transfer or kinetically limited conditions, and 
this review will focus on the mass transfer aspects of biological gas treatment techniques. Gas-liquid mass transfer is an object of active research in many areas. Efficient gas-liquid contacting is of great significance to many industrial applications, including biological gas treatment. When mass transfer is limited, the metabolic rate of the microorganisms decreases and the microorganisms may respond adversely to the resulting stress (Lebrero et al. 2010). A good understanding of the mass transfer behavior in bioreactors for gas treatment will result in improved modeling tools and more advanced reactor operations, which are important to maximize efficiency and minimize costs.

Traditionally, the enhancement of mass transfer in gasliquid contactors has been synonymous of an increase in power consumptions (Kreutzer et al. 2005a; Kreutzer et al. 2006). Unfortunately, in gas treatment where the treated gas flow can be as high as $10^{5} \mathrm{~m}^{3} \mathrm{~h}^{-1}$ and the footprint of the treatment equipment can be as large as a football field (Kennes and Veiga 2001), the energy required to obtain good interfacial contact area between gas and liquid in turbulent reactors can be immense. Therefore, a structure (packed-bed) is used in laminar contactors (biofilters and biotrickling filters) to maximize the contact surface, but the lack of mixing in these systems leads to the presence of heterogeneities within the packed-bed (Liu et al. 2005). This means that new strategies to increase mass transfer in gas treatment operations while minimizing the power consumption need to be developed.

This contribution reviews the mass transfer aspects of biotechnology for gas treatment in general terms, with an emphasis on the underlying principles and technically feasible methods for mass transfer enhancements of poorly water soluble compounds. Biofilters and biotrickling filter are by far the most applied biotechnologies for gas treatment, but face important limitations when applied for the treatment of poor water soluble compounds due mass transfer limitations. This mini-review focuses on biofilters and biotrickling filters, but aims at making the findings available for other developing biotechnologies for gas treatment, which are rarely applied often due to high power consumption (Shareefden and Singh 2005).

\section{Mass transfer or kinetically limited}

Understanding the rate-limiting steps in a system generates opportunities to optimize the design and operations of the system for a specific application. Typically, the reaction in the reactor is operating under either mass transfer or kinetically limited conditions.

In biological systems, such as biotrickling filters, bioscrubbers, and bubble-tank bioreactors with a mobile water phase that contains biomass, increasing the biomass concentration in the liquid phase would be a relatively simple way to determine whether the reactor is operating under mass transfer or kinetically limited conditions. When a change in the amount of pollutant removed per reactor volume (removal capacity) is seen at a sudden increased biomass concentration, the operation of the system is kinetically limited.

Another way to determine whether the reactor is operating under mass transfer or kinetically limited conditions is to change the operating temperature significantly and measure the efficiency at different gas velocities as shown by Barton et al. (1999). A large change in removal efficiency at a different temperature indicates kinetically limited as the mass transfer parameters solubility (increases with temperature), diffusion (increases with temperature), and Henry's constant (decreases with temperature) are somewhat temperature sensitive, but in general not as significant as the biodegradation parameters.

Measuring the volumetric removal capacity at different inlet volumetric loadings can be done to identify biological or mass transfer as potential rate-limiting step. When, in different experiments, the empty bed gas contact time is changed at constant substrate loadings, rate-limiting step discrimination could be created, especially when individual reactor sections are monitored as shown for example by Paca et al. (2009).

Cowger et al. (1992) developed a mathematical expression in order to separate mass transfer and kinetic limitations. They concluded that multiple experiments with various biomass concentrations still must be conducted to yield a definite conclusion of mass transfer-limiting conditions. Mathematical expressions, in particular the sensitivity analyses of dimensionless numbers (e.g., Damkohler number, Thiele Modulus, Peclet number), can be effective to clarify at least the interplay of mass transfer and biodegradation kinetics. The Damkohler number is defined as the ratio of the reaction rate to the mass transfer rate (the sum of advection and diffusion rates). The Thiele number is defined as a ratio of the reaction rate to the diffusion rate. The Peclet number is the ratio of the rate of advection to the rate of diffusion of compounds in a gas or liquid. Sensitivity analyses of dimensionless numbers in biological gas treatment models have been used by different authors (Goncalves and Govind 2009; Aroca et al. 2009) to demonstrate successfully whether the operation of the reactor was likely to be mass transfer or kinetically limited. Bosma et al. (1996) defined the bioavailability as the inverse of the Damkohler number for the case of dissolution controlled biodegradation and proved that the bioavailability number $(\mathrm{B} n)$ can be a useful tool to predict threshold concentrations below which no biotransformation is possible in soils slurries and percolation columns. 
It is important to note that in most situations a reactor is not either mass transfer or kinetically limited, but is a complex combination of both. It could very well be possible that the removal is substrate (mass transfer) limited deep in the biofilm, but kinetically limited near the aqueous/biomass phase. Also, as mass transfer and kinetic rates change along the height of reactor, the rate-limiting step might differ along the height of the reactor. Finally, as the biomass grows and could accumulate over time, the pore volume of the media can be reduced, reducing the interfacial area between the gas phase and the biofilm. In that case mass transfer limitation can be induced after a long time of operation as adeptly illustrated by Popat and Deshusses (2010).

In summary, although limited tools exist to determine what the rate-limiting step is in a biological gas treatment system, some authors have demonstrated that they can be used successfully.

\section{Defining mass transfer}

Mass transfer of the target compounds (pollutant and oxygen) from a gas phase into the liquid phase in biological gas treatment systems is often described with the two film theory from Lewis and Whitman (1924). This model uses two phases (e.g., gas and liquid) that have different concentrations and are not in equilibrium according to Henry's law. Only at the gas-liquid interface exists such equilibrium and the target compounds move from or to this interphase with a certain velocity, which is dependent on the type of compound and the properties of the gas and liquid phases. These velocities are defined in mass transfer rate coefficients. The overall mass transfer coefficient $\left(k_{\text {overall }}\right)$ is a combination of the different partial intrinsic mass transfer coefficients, often reduced to a mass transfer rate coefficient for the gas phase $\left(k_{\mathrm{G}}\right)$, a mass transfer rate coefficient for the liquid phase $\left(k_{\mathrm{L}}\right)$, and a mass transfer rate coefficient for the biofilm $\left(k_{\mathrm{B}}\right)$ as shown in Eq. (1).

$$
1 / k_{\text {overall }}=1 / k_{\mathrm{G}}+1 / k_{\mathrm{L}}+1 / k_{\mathrm{B}}
$$

The mass transfer coefficients are a function of the pollutant physical-chemical properties, the medium properties, the internal reactor characteristics as well as the operating conditions of the reactor system. In suspended reactors (bubble columns, airlift and stirred tanks), Eq. (1) continues being valid considering $k_{\mathrm{B}}$ as the resistance due to the water film around the cell or flocks of cells. If the resistance to the mass transfer in the gas and the biofilm is negligible (as might be expected in most cases, especially at low pollutant concentrations), the overall volumetric mass transfer rate $R\left(\mathrm{~g} \mathrm{~m}^{-3} \mathrm{~s}^{-1}\right)$ from the gas phase to the aqueous phase (where microorganisms are suspended or growing as a biofilm) takes place at a rate that is described (Koch 1990) in Eq. (2).

$R=k_{\mathrm{L}} a\left(C_{\mathrm{G}} / H-C_{\mathrm{L}}\right)=\left(D_{\mathrm{AL}} / \delta_{\text {film }}\right) a\left(C_{\mathrm{G}} / H-C_{\mathrm{L}}\right)$

where $D_{\mathrm{AL}}\left(\mathrm{m}^{2} \mathrm{~s}^{-1}\right), H$ (dimensionless), and $\delta_{\text {film }}(\mathrm{m})$ are the gaseous pollutant diffusivity in the liquid, the Henry coefficient, and the liquid film thickness, respectively. $C_{\mathrm{G}}$ and $C_{\mathrm{L}}$ are the pollutant concentrations $\left(\mathrm{g} \mathrm{m}^{-3}\right)$ in gas and liquid, respectively.

The term $k_{\mathrm{L}} a\left(\mathrm{~s}^{-1}\right)$ is a volumetric coefficient and consists of all concentration independent factors that determine the mass transfer rate, where $k_{\mathrm{L}}$ is the mass transfer coefficient $\left(\mathrm{m} \mathrm{s}^{-1}\right)$ and $a$ is the specific interfacial area $\left(\mathrm{m}^{2} \mathrm{~m}^{-3}\right)$ between the gas and liquid phase, regardless of whether a packing is present. When an additional phase (e.g., silicone oil) is added, the specific interfacial area between air and any phase other than water needs to be considered (see also the section on "Non-aqueous phase addition" further down this paper). $k_{\mathrm{L}}$ and $a$ are often difficult to obtain separate experimentally; however, $k_{\mathrm{L}} a$ can be obtained from macroscopic measurements.

Mass transfer takes place through both diffusion-the random Brownian motion of individual compounds in a medium - and by advection, in which compounds are transported by the larger-scale motion of currents in the medium. Convection is used to refer to the sum of advective and diffusive transfer. The diffusivity of lowmolecular weight compounds in gas are in generally in the range of $1 \times 10^{-5} \mathrm{~m}^{2} \mathrm{~s}^{-1}$ (Warneck 1988) and in water in the range of $1 \times 10^{-9} \mathrm{~m}^{2} \mathrm{~s}^{-1}$ (Harms and Bosma 1997). The diffusivity in biofilms will be far lower as, for example, Harms and Bosma (1997) reported diffusivity of pollutants in soils and sediments up to 12 orders of magnitude lower than in pure water.

From Eq. (2), it can be deduced that $R$ can be increased in different ways, for example (a) reducing the liquid film thickness by for instance reducing water flow (biotrickling filters) or increasing mixing (stirred tank bioreactor), (b) increasing the gas-liquid contact area through a support (liquid or solid) or by increasing mixing, and finally, (c) reducing the Henry coefficient, which increases the gradient of concentrations (driven force for the mass transfer); this can be done by increasing the affinity between the pollutant and liquid phase, for example by modifying the liquid phase composition.

Figure 1 shows a schematic representation of mass transfer in a bioreactor for gas treatment applications.

As observed in Fig. 1, in a packed or laminar reactor as a biotrickling filter, the pollutant or oxygen can be transferred from the gas flow $(F)$ to the cells through two water films or interfaces, one adhered to the package forming a biofilm, and other with the free water flowing through the package 
Fig. 1 An illustration of mass transfer typical for biological waste gas treatment processes
L

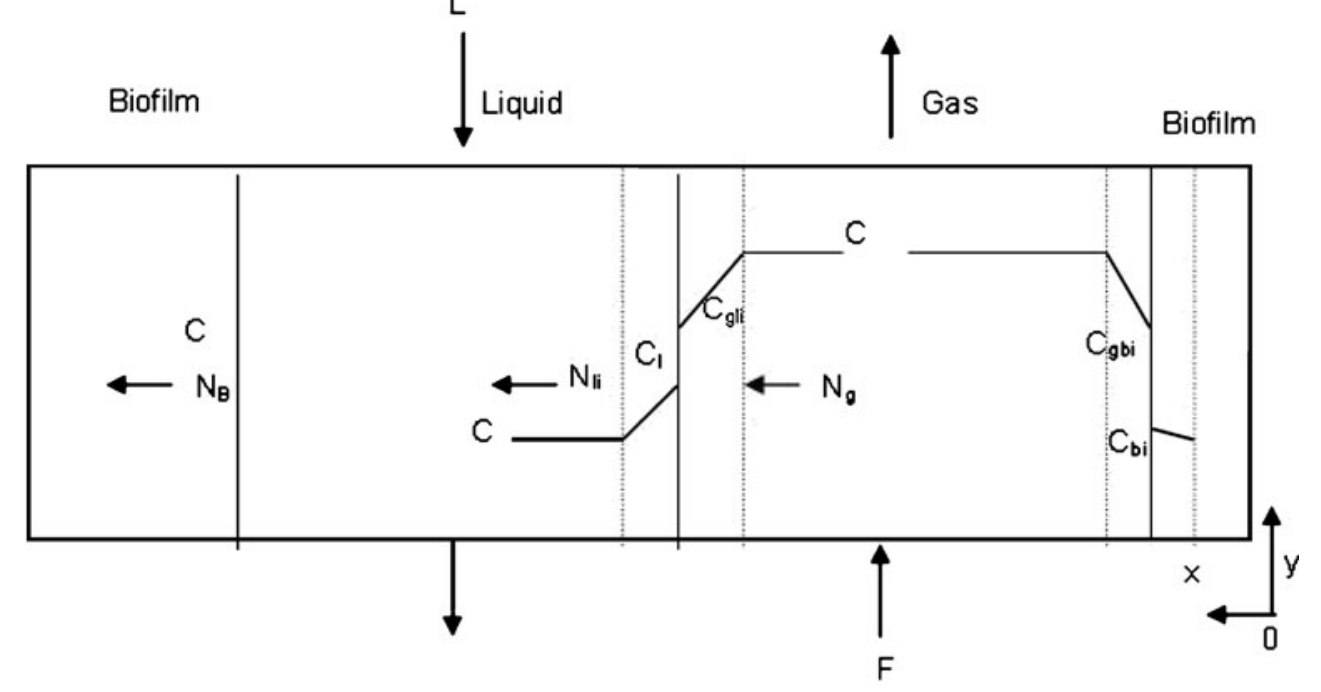

(L). In both interfaces, the pollutant (or oxygen) will be partitioned according to the thermodynamic equilibrium (Henry's law). Nevertheless, as the equilibrium exists only in the interface (Lewis and Whitman 1924), a concentration's gradient between the interface and the liquid bulk leads to a net mass transfer flux $(N)$. As the interface has no volume, the mass transfer accumulation is not possible and equality of fluxes can be established $\left(N_{\mathrm{g}}=\right.$ $N_{\mathrm{l}}=N_{\mathrm{B}}$ ). Figure 1 continues being valid to represent the mass transfer from the gas to liquid in a slurry or suspended bioreactor considering the biofilm on the liquid side as a single cell or flocks of cells dispersed, and the biofilm on the gas side as a single cell or flocks of cells in direct contact with a bubble.

\section{Determining mass transfer rates}

A biological gas treatment system contains typically a gas phase, a liquid phase, and a biofilm phase. The overall mass transfer coefficient is therefore a combination of different intrinsic partial mass transfer coefficients of these different phases. Below are briefly described some strategies used to estimate or measuring the partial mass transfer coefficients.

Intrinsic mass transfer coefficients are often calculated by means of empirical correlations, which are a function of the pollutant physical-chemical properties, the internal reactor characteristics (for example the packing material properties), as well as the operating conditions of the reactor system. Models describing biofilters or biotrickling filters often use mass transfer coefficients obtained from the empirical correlations developed for gas absorption, stripping or distillation using packing materials (Kim and Deshusses 2008). The empirical correlations for packed columns have been summarized by Wang et al. (2005). They compared the main correlations and concluded that the research on modeling the mass transfer prediction for packing materials still remains open as there is often a lack of a scientific basis. A distinction between the correlations to determine the mass transfer coefficient for random packing and structured packing materials was made. More modern (structured) packing materials have been developed that have a high mass transfer capacity at a lower pressure drop, which also comes along with a modified gas and liquid flow behavior. For future improvements of the empirical correlations, they recommended investigation of spatial liquid distribution inside the packing materials and improvement of the experimental setup to obtain more reliable data.

Also Hoffmann et al. (2007) showed discrepancy and inconsistency between different sources in literature data determining mass transfer parameters of packing materials used in absorption columns and concluded that standard procedures for measuring mass transfer of absorption systems are still required. Existing correlations are often made for relatively older packing elements. Rejl et al. (2009) concluded that, while much data exist, a lot of it has been measured using various different, and often erroneous, methods. This has resulted in the publication of vastly conflicting data and they suggested that the cause of discrepancies is most likely to be found in experimental technique. This is especially true for the sampling procedures (non-elimination of end effects in a packed column), and non-uniform distribution of the gas and liquid phases through the packed column is proposed as the main reasons for these discrepancies, which is an important lesson to future research on mass transfer in biological gas treatment systems. To improve the experimental technique used to determine mass transfer coefficients, it has been proposed (Hoffmann et al. 2007) that prehumidification to a saturation level be included to avoid both evaporation and condensation, maintain a constant 
temperature and pressure, prevent wall effects, and guarantee uniform liquid and gas distribution in the experimental setup.

As discussed by Kim and Deshusses (2008), systematic studies to determine mass transfer coefficients in biological gas treatment reactors are rare and mass transfer estimates are therefore often based on the large body of information obtained for traditional packing materials used in packed columns for gas absorption, stripping or distillation. The process in a biological gas treatment system is different and operating conditions are different, especially in relation to the liquid rate, but also to the gas rate. Kim and Deshusses (2008) concluded that both gas and liquid mass transfer coefficients for biofilters and biotrickling filter need to be modified, when they are based on empirical correlations that predict mass transfer coefficients for traditional packing columns. Also Dorado et al. (2009) concluded that there is a need for an accurate method to determine mass transfer parameters specifically in biological gas treatment systems after they showed that existing mathematical correlations for mass transfer coefficients fail to predict their experimentally obtained data.

Instead of using existing empirical mathematical correlations based on non-standardized experimental setups to predict the mass transfer coefficient, methods to measure the mass transfer coefficients directly on a specific reactor set-up can be used. Some of the most common methods are described below.

For the liquid-side mass transfer rate the absorption/ desorption of sparingly soluble gases, typically oxygen or carbon dioxide in/from water is generally used to measure $k_{\mathrm{L}} a$. As oxygen has a low solubility in water, there is no significant gas-side resistance. Linek et al. (1984) proved experimentally that the values of $k_{\mathrm{L}} a$ derived from oxygen absorption and desorption are identical. Desorption experiments were used as they were the more simple of the two to carry out. They kept the nitrogen gas flow rate through the packing column low $\left(0.03 \mathrm{~ms}^{-1}\right)$, but sufficient to keep the oxygen concentration in the effluent gas lower that $0.2 \% v / v$. This was done to ensure negligible back pressure of oxygen and negligible influence of axial dispersion in the gas phase.

The sulfite oxidation method (Linek and Vacek 1981), discussed by Suresh et al. (2009), can be used for oxygen mass gas-liquid transfer determination as a reliable, fast, and simple method as it does not require the measurement of dissolved oxygen in the liquid phase. A known amount of sulfite reacts fast in the presence of cobalt into sulfate when oxygen enters the liquid phase. Over time the sulfite concentration is determined by iodometric back-titration and the oxygen transfer rate calculated.

For the gas-side mass transfer rate, the gas-phase volumetric mass transfer coefficient, $k_{\mathrm{G}} a$, is typically measured using systems whose mass transfer resistance is limited to the gas phase. An instantaneous chemical reaction of a compound in the liquid phase can be used to determine directly the gas-side mass transfer coefficient. Different authors (Billet and Shultes 1999; Hoffmann et al. 2007, Linek et al. 2001) have used the absorption of $\mathrm{SO}_{2}$ from the gas phase in an aqueous $\mathrm{NaOH}$ solution, after Linek et al. (1995) proved that the absorption rate was independent from the $\mathrm{OH}$ concentration across a large concentration range down to $0.01 \mathrm{M}$.

Dorado et al. (2009) adopted a method from Heymes et al. (2006) to determine both the liquid and gas-side mass transfer coefficients. A packed column acted as a differential adsorption column with water continuously recirculated. A gas flow containing a target compound passes through the column upwards and the compound concentration in the gas inlet, gas outlet and liquid outlet is continuously monitored until the concentration in both the liquid and gas phase remain constant. The method has the advantage that it makes it is possible to use the target compound to be treated in the gas treatment system. They included suggestions from Hoffmann et al. (2007) to minimize most common errors found in mass transfer studies. Dorado et al. (2009) pointed out that in typically used biological gas treatment systems (biofilter and biotrickling filters), the gas phase resistance should not be neglected at high gas contact times (low gas velocities), probably because diffusion in the gas phase is the dominant process rather than advection.

Cowger et al. (1992) developed a mathematical expression in order to separate mass transfer and kinetic limitations and elegantly showed that when multiple experiments with various cell concentrations are conducted under mass transfer-limiting conditions, the overall mass transfer coefficient can be obtained from removal efficiency measurements at different gas flows.

Once the volumetric mass transfer coefficient has been determined, the overall volumetric mass transfer rate $R$ in Eq. (2) can be calculated for the maximum concentration gradient, considering that under mass transfer-limiting conditions the dissolved concentration of the target compound is zero as it is degraded immediately by microorganisms.

\section{Factors influencing mass transfer}

The intrinsic mass transfer coefficient is a function of the pollutant physical-chemical properties, the medium properties (e.g., viscosity, salt and organic content), the internal reactor characteristics (e.g., gas and liquid flow behavior, surface area and wettability of the packing material), as well as the operating conditions (e.g., gas velocity, liquid velocity, $\mathrm{pH}$, and temperature). Some of these parameters 
and their relevance to biological gas treatment systems are discussed below.

The overall mass transfer coefficient $k_{\mathrm{L}} a\left(\mathrm{~s}^{-1}\right)$ is directly related to the effective interfacial area $\left(\mathrm{m}^{2} \mathrm{~m}^{-3}\right)$. The effective interfacial area is often different from the specific surface area $(a)$ of packing material, as part of the packing surface might not be wetted or could be located in a dead zone not being effective for mass transfer. Water droplets and swirls on the other hand could increase the effective interfacial area. The effective interfacial area depends on the operation conditions of the system. Physical methods such as electro-resistivity, light transmission, and reflection techniques can be used, but usually the effective interfacial area is determined by mass transfer measurements in the presence of a fast chemical reaction as proposed by Joosten and Danckwerts (1973). This method uses the absorption of relatively low concentrations $(<1 \% v / v)$ carbon dioxideenriched air in $1 \mathrm{M} \mathrm{NaOH}$ solution. Rejl et al. (2009) showed that this method can only be used when the gas velocity is $>0.5 \mathrm{~ms}^{-1}$, otherwise the gas phase resistance becomes too large. Although the required gas velocity is in the range $\left(0.3-3 \mathrm{~ms}^{-1}\right)$ typically found in packed columns used for absorption (e.g., chemical scrubbers) or distillation and evaporation, it is too high for most biological gas treatment systems, which normally operate in the range $0.02-0.4 \mathrm{~ms}^{-1}$. Therefore, this standard method might be less suitable to determine the exact effective interfacial area in a biological gas treatment system.

Packing materials have specific surface areas and not all parts of the surface may contribute to mass transfer as, for example, not all parts are wetted at all times. The wetted specific surface area is a percentage of the total specific surface area of the packing material, also sometimes expressed as wettability factor, and is dependent on factors such as gas and liquid flow. This wettability is critical for the overall performance for packed columns used for absorption (e.g., chemical scrubbers) or distillation and evaporation, which might not necessarily be true for all biological gas treatment systems. The catalytic reaction in a chemical scrubber normally takes place in the liquid phase, while the catalytic reaction in most common used biological gas treatment systems (biofilter and biotrickling filter) takes place not so much in the liquid phase but for the majority in the biofilm, even in biotrickling filters with continuous recirculation (Cox et al. 2000). Also due to biological growth on the packing material the surface becomes hydrophilic and therefore wettability is much higher than the bare surface properties.

Direct gas-biofilm mass transfer is preferred when the catalytic reaction takes place in the biofilm. In a biological system, the liquid is required to prevent drying out of the biofilm and is a transport medium for the supply of nutrients and sometimes the removal of degradation products (e.g., sulfuric acid). Transport of water over the biofilm is necessary to maintain a high water activity, but can actually form an extra barrier for mass transfer as illustrated by Popat and Deshusses (2010) among others where the elimination capacity in their biotrickling filter experiment was the highest when recirculation of the liquid was temporarily stopped.

Another important factor is the air distribution, which is most of the time not taken into consideration when modeling biofiltration. Most models presume that air flow within the reactor is plug flow (Devinney and Ramesh 2005), which might be a too simplified assumption. Prenafeta-Boldu et al. (2008) showed the importance of the presence of stagnant air zones in different packing materials and demonstrated that increasing airflows reduces stagnant air zones and can consequently reduces potential diffusion limitations.

Many biological gas treatment models are based on the equilibrium according to Henry's law at the gasliquid interface. The presence of biomass can have a substantial effect on this equilibrium as illustrated by Davison et al. (2000) and Barton et al. (2003) and further discussed by Barton et al. (2008). High biomass or organic levels of more than $15 \mathrm{~g}$ dry weight per liter can be found in biofilms present in biological gas treatment systems. The overall mass transfer is directly related to the Henry coefficient and measurements of Henry coefficients and maximum solubility in aqua-biomass mixtures are necessary to compensate for the additional organic constituents. The Henry coefficient of, for example, toluene decreased by a factor of 30 compared to pure water when the biomass content was $30 \mathrm{~g}$ dry weight per liter and its maximum solubility increased by a factor 4 compared to pure water when biomass content was $0.25 \mathrm{~g}$ dry weight per $\mathrm{mL}$. At $100 \mathrm{~g}$ biomass per liter, the Henry's value for trichloroethene was only about $2 \%$ of that in pure water and even at relatively low biomass levels, such as $10 \mathrm{~g}$ per liter, the partitioning constant was less than $10 \%$ of that in pure water. In the absence of these experimental data, Barton et al. (2008) recommended use of octanol-water partitioning constants rather than the gas-water partitioning constants. Although the authors showed that the use of octanol-water partitioning constants is not a reliable predictor, they illustrated that the effect of biomass on the Henry coefficient (trend and order of magnitude) is described correctly.

Miller and Allen (2005) discussed the transport of hydrophobic compounds through biofilms and concluded that a biologically mediated transformation of a hydrophobic compound into a more soluble, less volatile by-product that then can penetrate deeper into the biofilm can take place. Not only the presence of biomass, but also the presence of extracellular metabolites such as biosurfactants 
could, for example, affect the overall mass transfer (Painmanakul et al. 2005).

\section{Bioreactor configurations and mass transfer enhancement strategies}

Basically, we can divide the bioreactors for gas treatment operations in two groups: turbulent and laminar contactors. In turbulent contactors (stirred tanks, bubble columns, or airlift reactors), the energy supplied to the system is used to break bubbles and to reduce the liquid film (increasing $a$ and reducing $\delta_{\text {film }}$ in Eq. 2, respectively); nevertheless, above an optimal value of power input most of the energy is dissipated in the liquid through eddies that do not contribute to the mass transfer (Kreutzer et al. 2006) increasing the operation costs of process. In laminar contactors (biofilters and biotrickling filters), a structure (media) is used to provide the gas/ liquid contact area, the power consumption in these systems can be 1 or 2 orders of magnitude lower than in turbulent contactors (Rocha-Rios et al. 2010), and this explains why for commercial applications, biofilters, and biotrickling filters continue being the most used technologies. Nevertheless, the main limitation of laminar contactors is related to mass transfer limitations of poorly water soluble compounds. Typical removal efficiencies of compounds as acetone, ethanol or toluene are higher than 90\% (Adler 2001) where the removal efficiencies for poorly soluble compounds as methane are typically lower than 70\% (Rocha-Rios et al. 2010) and requiring large gas contact times in the reactor.

Unlike the turbulent systems where the suspensions gas/ liquid and cells/liquid can be assumed perfectly mixed and the mass transfer rate can be expect to be similar at all points of the reactor, in laminar contactors (biotrickling filters and biofilters) operational problems are often caused by heterogeneities generating gradients in pollutant, water content, and biomass concentrations as well as gradients in nutrient concentration and $\mathrm{pH}$ through the package (Ramirez-Lopez et al. 2000). Moreover, due to the presence of heterogeneities throughout the reactor, especially the water content causes differences in the support's compaction resulting in flow channelization and possible anaerobic regions formation (Cardenas-Gonzalez et al. 1999). To avoid compaction problems in random laminar contactors, new supports covering a wide variety of specific surface areas and porosity have been developed reducing the pressure drop problems in these systems. An interesting laminar contactor that prevents the formation of heterogeneities with minimal power consumption is the capillary reactor when operated under Taylor flow and is discussed later in this paper.
As technologies for biological gas treatment are applied mostly at relatively low gas concentrations, we estimate that they are nearly always subject to at least partial mass transfer limitation. Mass transfer limitation of either substrate or oxygen can occur near the aqueous/biomass phase, deep in the biofilm, or just near the exit of the system due to the low partial pressure of the target compound. Biotechnology for gas treatment is accepted as an economical and reliable air pollution control technology for treating gases contaminated mainly with relatively low concentrations. The extension of its application field is limited in many cases by the mass transfer of especially hydrophobic target compounds. Below we briefly review some of the strategies which we have shown to be technical feasible to overcome mass transfer limitation.

\section{The action of fungi}

Fungi have the advantage that their aerial mycelia form a larger surface area (see Eq. 2) in the gas phase than bacterial biofilms, which is suggested to facilitate the uptake of hydrophobic volatile compounds (Cox 1995). Wosten et al. (1999) and Wosten (2001) illustrated the role of hydrophobins in fungal growth, how they influence hydrophobicity of the aerial mycelia of fungi and showed that the presence of water hinders the development of the aerial mycelia. Filamentous fungi secrete hydrophobins at hydrophobic-hydrophilic interfaces such as gas-water to form an amphipathic coating that lowers the surface tension, which enables hyphae to breach the water-gas interface. This mechanism can be used by fungi for direct pollutant consumption from the gas phase avoiding the mass transfer resistance in the liquid.

Arriaga and Revah (2009) determined the partition coefficient between hexane and (wet or dried) fungal samples (perlite + Fusarium solani) and between hexane and dried bacterial samples (perlite + consortium). The results indicated that partition coefficient of hexane was nearly an order of magnitude lower for fungal (more absorption) than bacteria films, and it was lower for dry fungal samples than for the wet samples. This proves also that direct gas-biofilm mass transfer is preferred, minimizing the gas-liquid-biofilm path for the transfer of the target compound. Vergara-Fernandez et al. (2006) illustrated that the surface hydrophobicity of the fungi mycelia can change over time and increase consistently with more hydrophobic substrates.

Besides relatively higher mass transfer rates of hydrophobic compounds in fungal biofilters than in bacterial biofilters, another advantage is that fungi are more resistant to drying out and acidification. Fungi biofilters have shown to be significantly more robust to poor moisture control in the biofilter (Cox 1995; Kraakman et al. 
1997; Groenestijn et al. 2001). This makes it possible to operate a fungal biofilter under relatively dry condition reducing the liquid film thickness ( $\delta_{\text {film }}$ in Eq. 2). Different authors (Groenestijn et al. 2001; Arriaga and Revah 2005a, b; Spigno et al. 2003; Jin et al. 2007) showed relatively high removal capacities of hydrophobic compounds in fungal biofilter and illustrated the improved robustness during typical upsets that can be experienced in an industrial application like interruption of water, gas, and nutrient supply. Table 1 presents different studies where a fungus, as a dominant organism, was used for pollutant degradation.

High conversion rates come with increased biomass growth in biofilters and high pressure losses are reached sooner with filamentous fungi than with non-filamentous microorganisms, eventually causing clogging and channeling problems in the biofilter. Innovative solutions, such as the addition of higher organisms, are explored and described by Groenestijn et al. (2001) and Woertz et al. (2002a, b). This "grazing" concept showed that the use of higher organisms (mites) in a fungal biofilter allowed maintenance of a low pressure drop and minimize power consumption. The fungi grow partially in the pores of the media (perlite) protected against predation, while the mites grow by "grazing" at a relatively low biomass yield and are partly washed out as a result of the discontinuous irrigation. Simultaneously, the performance of the fungal biofilter was significantly higher compared to the control fungal biofilter without mites.

Non-aqueous phase addition

The addition of a non-aqueous phase liquid (NAPL) such as for instance an organic solvent can overcome design and operational limitations of biological systems. Interesting advances have been made over the last 15 years in different biological systems that make use of an organic phase as transfer vectors, despite the lack of knowledge of the exact

Table 1 Studies on bioreactor systems for gas treatment with fungi

\begin{tabular}{lll}
\hline System & Target compound & Reference \\
\hline Fungal biofilter & Styrene & Cox (1995) \\
Fungal biofilter & Styrene & Kraakman et al. (1997) \\
Fungal biofilter & Styrene & Groenestijn et al. (2001) \\
Fungal biofilter & Toluene & Woertz et al. (2002a) \\
Fungal biofilter & Nitric oxide & Woertz et al. (2001) \\
Fungal biofilter & Hexane & Arriaga and Revah (2005a, b) \\
Fungal biofilter & VOCs & Spigno et al. (2003) \\
Fungal biofilter & Alpha-pinene & Jin et al. (2007) \\
Fungal biofilter & Hexane & Arriaga and Revah (2009) \\
\hline
\end{tabular}

mechanisms (Déziel et al. 1999; Quijano et al. 2009a). The so-called two-phase partitioning bioreactors make use of an extra phase (solvent) to enhance the productivity or facilitate the downstream processing from bioprocesses. The concept is applied either to control the delivery of a (sometimes toxic) substrate dissolved in the non-aqueous phase or to continuously extract a bio-product (Ratledge 1977; Wubbolts et al. 1996). This technology has now been researched for the treatment of poorly water soluble gaseous compounds (Yeom and Daugulis 2001; Davison and Daugulis 2003; Arriaga et al. 2006). The non-aqueous phase (for example a large branched alkane, silicone oil or a plastic polymer), which is selected as immiscible, nonvolatile, non-toxic, non-biodegradable, and with high affinity by the target compound (Quijano et al. 2010a; Hernandez et al. 2010; Rocha-Rios et al. 2011a), is added to the aqueous phase with the aim of improving the transfer of hydrophobic substrates from the gas phase, buffering fluctuations in the gaseous concentrations or reducing the toxicity for the microorganisms.

The review by Muñoz et al. (2007) shows that the main transfer mechanisms are based on the hypothesis that the substrate uptake takes place in the aqueous phase. Resistance of the diffusion through the liquid boundary layer is counteracted both by the increase in the interfacial area for mass transfer and the enhanced accumulation of the target compound in the organic phase, which acts as a reservoir. They also noted that various authors have observed bacterial adhesion at the non-aqueous/aqueous interface (Rosenberg 1991; McLeod and Daugulis 2005) and have suggested that direct pollutant and oxygen uptake from the non-aqueous phase improved the overall removal efficiency of the process. It is also known that many microorganisms are also capable of producing biosurfactants that can solubilize the hydrophobic compounds and possibly improve uptake (Hamme et al. 2003; McLeod and Daugulis 2005). With the addition of a solvent, the overall change in volumetric mass transfer coefficient $\left(k_{\mathrm{L}} a\right)$ depends on the relative magnitudes of effects on a new resistance (organic phase) added to the overall system, which is usually higher than that of water due to a higher viscosity of the NAPL, and the different interfacial contact areas that can be present (gas-water, gas-oil, oil-water, cell-gas, cell-water, cell-oil).

Table 2 shows different studies where an organic phase was added to increase the pollutant or oxygen transfer from the gas to the liquid.

In turbulent reactors, for the organic phase addition to be effective, the increase in the different interfacial contact areas must overcome the general increase in the mass transfer resistance by the organic phase addition (Clarke and Correia 2008; Quijano et al. 2010b). It has been shown in stirred tank reactors that silicone oil drops can increase 
Table 2 Studies on bioreactor systems with a non-aqueous phase addition to increase mass transfer and consumption of poorly water soluble compounds

\begin{tabular}{lll}
\hline System & Target compound & Reference \\
\hline Biotrickling filter with 5\% silicone oil & Hexane & Groenestijn and van Lake (1999) \\
STR with solid polymer & Benzene & Daugulis et al. (2003) \\
STR with 33\% hexadecane & Benzene & Davison and Daugulis (2003) \\
Biotrickling filter with 20\% silicone oil & Styrene & Djeribi et al. (2005) \\
STR with 33\% hexadecane & Benzene & Nielsen et al. (2005) \\
STR with 10\% silicone oil & Hexane & Muñoz et al. (2006) \\
Fungal bioreactor with 1\% silicone oil & Hexane & Arriaga et al. (2006) \\
Airlift bioreactor and STR with silicone oil & Oxygen & Quijano et al. (2009b) \\
Thermophilic biotrickling filter & Alpha-pinene & Montes et al. (2009) \\
with 5\% silicone oil & & \\
Airlift bioreactor with 10\% silicone oil and beads & BTEX & Littlejohns and Daugulis (2009) \\
STR with 1\%, 5\%, or 10\% silicone oil & Methane & Rocha-Rios et al. (2010) \\
STR and biotrickling filter with 10\% silicone oil & Dichloromethane & Bailon et al. (2009) \\
STR with silicone oil and beads & Hexane & Hernandez et al. (2010) \\
Capillary bioreactor with 5\% and 10\% silicone oil & Methane & Rocha-Rios et al. (2011b) \\
\hline
\end{tabular}

the gas-water interfacial contact area through two effects, first, colliding with the gas bubbles and breaking them (Galindo et al. 2000; Quijano et al. 2010b), and second, by a reduction in the gas-water surface tension (Quijano et al. 2010b). The first effect is increased by the stirring rate (power consumption) in the system as demonstrated by Rocha-Rios et al. (2010) who observed no effect of silicone oil addition ( 5 and $10 \%, v / v$ ) on methane degradation at $200 \mathrm{rpm}$, while a positive effect was observed at 500 and $800 \mathrm{rpm}$.

Obtaining a mathematical model to describe the effect of a NAPL in these systems is still a challenge. The first attempt to model the degradation of a gaseous pollutant (hexane) in a two-phase partition bioreactor was developed by Bordel et al. (2010) considering that all hexane degradation takes place in the aqueous phase. This assumption cannot be valid for more hydrophobic compounds like methane as Han et al. (2009) reported that most of Methylosinus trichosporium cells using methane as the sole carbon source were growing attached to the paraffin oil drops used as a mass transfer vector. Rocha-Rios et al. (2009, 2010) proposed that a possible direct uptake of methane could be important to explain the increase in the elimination capacities observed. Contrasting results were reported by Quijano et al. (2009b) using silicone oil as oxygen transfer vector, who found through sulfite oxidation determinations, that $90 \%$ of the oxygen transfer was airwater and just 10\% air-oil-water. Therefore, more studies are required to clarify this particular finding. Moreover, the empirical correlations that are used to estimate $k_{\mathrm{L}} a$ properly in turbulent one-liquid phase systems, may be misleading in two-phase partition systems as soon as the viscosity exceeds ten times the $1 \mathrm{mPas}$ viscosity of pure water (Delaloye et al. 1991; Rocha-Rios et al. 2010).
Although Dorado et al. (2009) showed that at low gas velocities the mass transfer can be determined by the gas phase, the mass transfer is usually limited by the liquid-side resistance. Experiments by Heymes et al. (2006) showed that the $k_{\mathrm{L}} a$ of a system using viscous liquids depends on the liquid velocity but also on the gas velocity. This behavior has also been observed by the few authors who have used viscous fluids in their experiments and is contrary to all the authors who have worked on lowviscosity fluids. The physical characterization of the liquid phase plays an important role in hydrodynamics and mass transfer kinetics. Gomez-Diaz and Navaza (2003) showed, for example, that the presence of polymers (carboxymethyl cellulose) influences the viscosity and thereby the mass transfer. It is therefore clear that the influence of viscosity on the mass transfer phenomenon is considerable and should be taken into account at the addition of a solvent.

The stability of a non-aqueous solvent under long-term operation is, in general, unclear and its application could be limited by the fact that the solvent can be slightly volatile. To overcome this, highly stable solid polymers based on copolymers of polyurethane, vinyl acetate, and ethylene (e.g., Kraton, Elvax, Desmopan) as the non-aqueous phase has been proposed (Daugulis et al. 2003) as well as hydrophobic packing materials (Montes et al. 2011). Although slower to respond to sudden changes in pollutant concentration compared with the liquid-liquid systems (Boudreau and Daugulis 2006), the overall biological system can be more stable and possibly more cost effective.

In laminar reactors, different heterogeneities are produced in the package of biofilters and biotrickling filters during the operation (biomass, humidity, air canalization, etc.; Cardenas-Gonzalez et al. 1999). When an organic phase 
(like silicone oil) is added, its distribution through the package is affected by these heterogeneities generating zones in the package with higher oil content (this effect is enhanced by the higher viscosity of the oil than water). This irregular oil distribution, which is a consequence of mixing lack in the package, will be increased as a function of the operation time, unless a periodic interruption of the bioreactor's operation is made to mix the package. Unlike the turbulent reactors where the organic phase addition has increased generally the removal efficiency of hydrophobic pollutants (Table 2), inconclusive results have been obtained in laminar contactors for the same pollutants at similar pollutant loadings. In the laminar reactors shown in Table 2, an increase in elimination capacity was reported with the organic phase addition; however, in most of these studies a higher pollutant load was fed in the two-phase systems, producing similar removal efficiencies that in control systems (without organic phase addition). Fazaelipoor and Shojaosadati (2002) observed no effect of silicone oil addition $(20 \% v / v)$ on biofiltration of a mixture of hydrophobic compounds with hexane as the principal component $(80 \%)$ at low inlet concentrations $\left(1 \mathrm{gm}^{-3}\right)$, but when the inlet concentration was increased at $3 \mathrm{gm}^{-3}$, an improvement of $10 \%$ in the removal efficiency was obtained. A strategy to avoid the addition of an organic phase in laminar contactors is selecting a packing material with similar properties (fundamentally high affinity by the pollutant and oxygen) (Montes et al. 2011). Another strategy to avoid the formation of heterogeneities caused by a random distribution of the packed particles, is changing to a structured package (capillary bioreactor) as proposed by Kreutzer et al. (2005b and 2006), Ebrahimi et al. (2005a) and Rocha-Rios et al. (2011b) as discussed further up in this paper.

Often a non-aqueous phase liquid like silicone oil does not mix well with water due to differences in hydrophobicity and density, which induces partitioning between the two phases. If not controlled, phase separation could very well induce a reduction of the overall biodegradation efficiency. Stable emulsions are required and might require additional mixing. We have seen that the stability of a silicone oil and water emulsion improves over time in the presence of microorganisms (Rocha-Rios et al. 2011b).

The non-aqueous phase should be selected based on its cost, enhanced partitioning properties towards the target compound(s), immiscibility, viscosity, volatility, safety, nontoxicity, and non-biodegradability. Although data on costs, immiscibility, viscosity, toxicity, volatility, safety, and biodegradability are available for different solvents and solid polymers (Quijano et al. 2010a; Hernandez et al. 2010; Rocha-Rios et al. 2011a), sufficient data are at this moment not yet available to predict the partitioning properties of non-aqueous phase towards many target compounds.

Taylor flow turbulence

The traditionally used biological gas treatment methods (biofilters and biotrickling filters) can be called laminar contactors. Laminar flow occurs when a gas or liquid flows in parallel layers, with minimal disruption between the layers. Laminar flow is a flow regime characterized by high diffusion and low advection and is the opposite of turbulent flow. The mass transfer rate through a water film by diffusion is relatively slow when compared to diffusion through gas (in general by a factor of approximately 10,000). Therefore improved convection by advection (for example through mixing) will improve mass transfer through a water film.

Considerable effort has been expended in the search of less energy-intensive reactors to further enhance mass transfer rate. Capillary reactors combine good mass transfer with low pressure drop, two important factors affecting cost effectiveness for many industrial applications. Capillary reactors are structures of parallel straight microchannels (capillary channels) separated by a thin wall. The hydrodynamics of gas-liquid flow in capillary channels have been studied within the context of chemical reaction engineering (Nijhuis et al. 2002; Kreutzer et al. 2005b; Shao et al. 2010). A capillary reactor is a reactor where the capillary forces, created by the capillary channel, become dominant over other forces as such gravity and viscosity. For air-water contractors, this means a capillary channel with a diameter around $5 \mathrm{~mm}$ or smaller (Kreutzer et al. 2005b). The preferred flow patron, called segmented flow or Taylor flow, is a bubble train of alternating liquid slugs and air bubbles with gas and liquid flowing downwards or upwards co-currently. Although the airflow seems to be laminar, the internal liquid circulation increases the mass transfer from the gas phase to the liquid phase where a plug flow (no macromixing and axial dispersion) is combined with good mass transfer (local mixing) and low pressure drop (Kreutzer et al. 2005b). A bioreactor using a monolith support operated under Taylor flow conditions is an example of a capillary bioreactor.

The rate of transport of the compounds through a medium is characterized by resistance to the medium. Input of energy can overcome resistance, such as, for example, mixing in bubble-tank bioreactor to break up air bubbles and thereby increasing the interfacial surface area of the gas bubble with the liquid. The physical input of energy in a system is always limited by the equipment required for the energy input, which will operate with a specific optimal efficiency dependent on its operating conditions. The specific efficiency for example of a mixer is typically around $60-70 \%$ when operated under optimal conditions. 
Increased energy consumption results in increased cost of operation, which should be minimized for industrial applications. The mass transfer using Taylor flow is relatively energy efficient, mainly because no energy is required to maintain the small gas bubble size. Figure 2 shows the mass transfer rate versus energy input for biotrickling filtration and capillary reactors.

The data for capillary reactors were obtained from Kreutzer et al. (2005a), who illustrated, with an order of magnitude analysis, that the relation between mass transfer rate and the power input per reactor volume for a capillary reactor can be expressed as $k_{\mathrm{L}} a \approx 0.1 \times(\mathrm{P} / \mathrm{V})^{0.25}$, with $\mathrm{P}$ the power input (watt) and $\mathrm{V}$ the reactor volume $\left(\mathrm{m}^{3}\right)$. The data for the biotrickling filter were obtained from Kim and Deshusses (2008), who were the first to conduct a systematic study to actually measure mass transfer rates in the most common used biotechnologies for gas treatment (biofiltration and biotrickling filtration).

Capillary reactors are becoming increasingly significant as multiphase reactors, considering the advantages that they offer, in comparison with conventionally used trickle beds or biofilters for a host of processes (Liu et al. 2005). These advantages, which include low pressure drop, high gasliquid mass transfer rates, and minimum axial dispersion (plug flow), stem from the uniquely structured multichannel configuration of capillary channels. Some studies have shown that the use of capillary reactors, in lieu of trickle beds, results in higher productivities and a very significant reduction in reactor size for specified chemical processes (Nijhuis et al. 2002; Stankiewicz 2001).

Ebrahimi et al. (2005a, b) studied the biomass growth in capillary (monolithic) bioreactors and concluded that biofilm formation can be minimized by a proper choice of operation and that periodic biomass removal is relatively simple by ringing with water at moderate pressures. RochaRios et al. (2011b) illustrated that the addition of a nonaqueous phase (silicone oil) in a capillary bioreactor removing methane is beneficial, which shows the potential of capillary bioreactor for the treatment of compounds with poor water solubility.

\section{Conclusions}

Understanding the mass transfer behavior in bioreactors for gas treatment is highly relevant to obtain improved modeling tools and more advanced reactor operations. Different aspects have been discussed and it shows that work is still needed to fully understand the phenomena of mass transfer in a bioreactor for gas treatment. Studies to determine mass transfer coefficients in biological gas treatment reactors are rare and mass transfer estimates are therefore often derived from studies on packing materials in systems (e.g., absorption columns) with different process conditions. The influence of biomass on the partitioning coefficient of the target compound in a gas-liquid and gasbiofilm interface in biological gas treatment processes also needs more detailed study.

Some of the strategies that have shown to be technical feasible to overcome mass transfer limitation have been reviewed. Although the mechanisms of mass transfer enhancement are not fully elucidated and different technical challenges need to be resolved before they can be used at full-scale, several promising strategies to improve mass transfer while minimizing power consumption mark the future trend. In random package contactors, these strategies
Fig. 2 Mass transfer and power consumption in monolithic reactors compared to biotrickling filtration

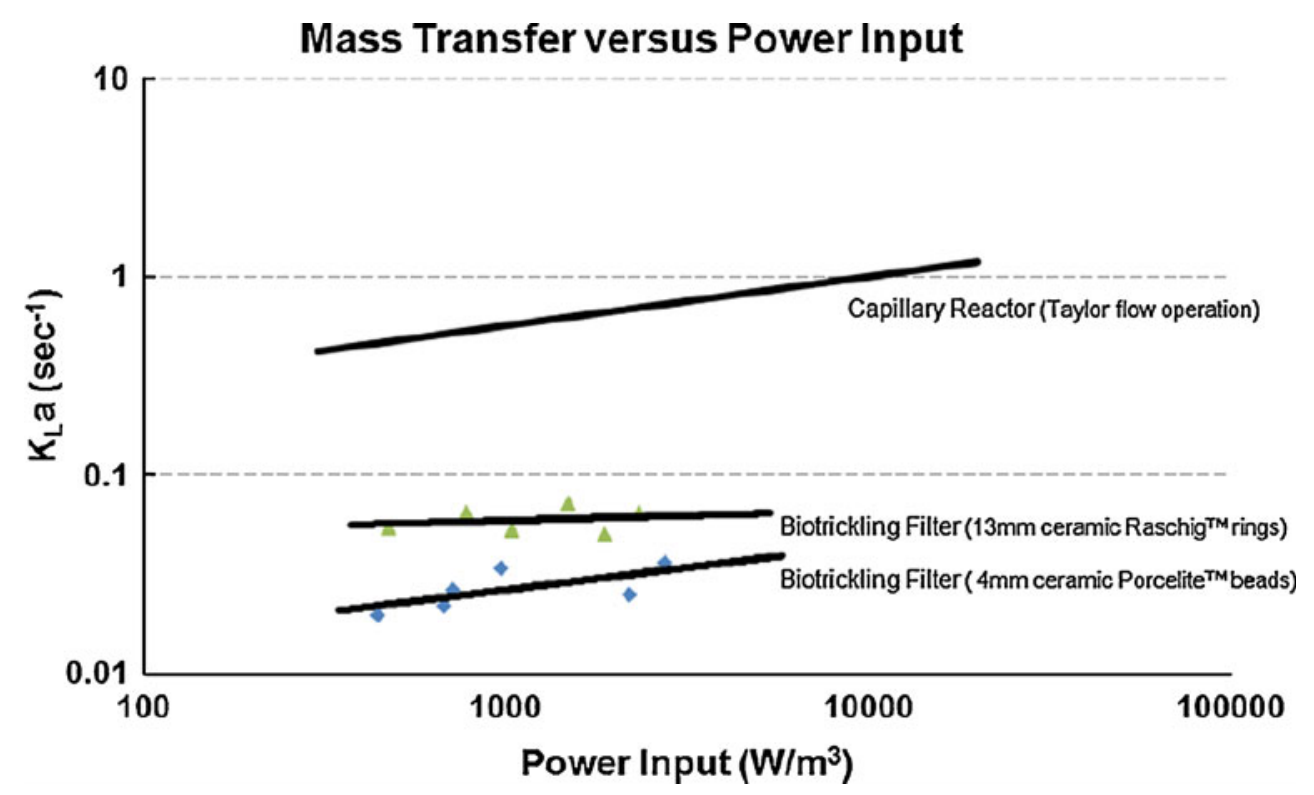


include the use of inorganic supports with high specific surface areas and high porosities, the action of fungi and the addition of a liquid organic phase. Nevertheless, the addition of an organic phase, more viscous than water, may increase the formation of heterogeneities through the bed affecting the pollutant transfer rate. This could explain why different authors have reported either positive or negative effects of the organic phase on mass transfer in these systems. An interesting alternative is the absorption of the pollutant in a solid polymer which can be used as support in a biofilter or biotrickling filter. Finally, a promising strategy to increase mass transfer of poorly water soluble compounds with minimal power requirements is the capillary bioreactor, but more study is necessary to scale-up this system to commercial applications.

Acknowledgment The financial support for this work was given by the Netherlands Organisation for Scientific Research (NWO), Bioway International b.v., and the Technical University Delft, the Netherlands under NWO-Casimir project 018.002.019.

Open Access This article is distributed under the terms of the Creative Commons Attribution Noncommercial License which permits any noncommercial use, distribution, and reproduction in any medium, provided the original author(s) and source are credited.

\section{References}

Adler SF (2001) Biofiltration a primer. Chem Eng Prog 4:33-41

Aroca G, Silva J, Morales M et al. (2009) Sensitivity analysis of the model that describes the biofiltration of mixture of $\mathrm{H}_{2} \mathrm{~S}$ and DMS. In: Proceeding of the 3rd International Congress on Biotechniques for Air Pollution Control. Bartacek J and Lens PNL. (eds.), pp. 169-171. September 28-30, Delft, The Netherlands

Arriaga S, Revah S (2005a) Removal of n-hexane by Fusarium solani with a gas phase bioreactor. J Ind Microbiol Biotechnol 32:548553

Arriaga S, Revah S (2005b) Improving hexane removal by enhancing fungal development in a microbial consortium biofilter. Biotechnol Bioeng 90:107-115

Arriaga S, Revah S (2009) Mathematical modeling and simulation of hexane degradation in fungal and bacterial biofilters: effective diffusivity and partition aspects. Can J Civil Eng 36:1919-1925

Arriaga S, Muñoz R, Hernández S, Guieysse B, Revah S (2006) Gaseous hexane biodegradation by Fusarium solani in two liquid phase packed-bed and stirred tank bioreactors. Environ Sci Technol 40:2390-2395

Bailon L, Nikolausz M, Kaster M, Veiga MC, Kennes C (2009) Removal of dichloromethane from waste gases in one- and twoliquid-phase stirred tank bioreactors and biotrickling filters. Water Res 43:11-20

Barton JW, Davison BH, Klasson KT, Gable CC (1999) Estimation of mass transfer and kinetics in operating trickle-bed bioreactors for removal of VOCs. Environ Prog 18:87-92

Barton JW, Vodraska CD, Flanary SA, Davison BH (2003) Partitioning of BTEX constituents and chloroorganics in high-biomass systems. Environ Prog 22:95-102

Barton JW, Vodraska CD, Flanary SA, Davison BH (2008) Solubility of toluene, benzene and TCE in high-microbial concentraion systems. Chemosphere 73:1737-1740
Billet R, Shultes M (1999) Prediction of mass transfer columns with dumped and arranged packings - updated summary of the calculation method of Billet and Shultes. Chem Eng Res Des 77:498-504

Bordel S, Hernandez M, Villadeverde S, Muñoz R (2010) Modelling gas-liquid VOCs transport in two-liquid phase partitioning bioreactors. Int J Heat Mass Transfer 53:1139-1145

Bosma TNP, Middeldorp PJM, Schraa G, Zehnder AJB (1996) Mass transfer limitation of biotransformation: quantifying bioavailability. Environ Sci Technol 31:248-252

Boudreau NG, Daugulis AJ (2006) Transient performance in twophase partitioning bioreactors treating a toluene contaminated gas stream. Biotechnol Bioeng 94:448-457

Cardenas-Gonzalez B, Ergas SJ, Switzenbaum MS (1999) Characterization of compost biofiltration media. J Air Waste Manag Assoc 49:784-793

Clarke KG, Correia LDC (2008) Oxygen transfer in hydrocarbonaqueous dispersions and its applicability to alkane bioprocesses: a review. Biochem Eng J 39:405-429

Cowger JP, Klasson KT, Ackerson MD, Clausen E, Caddy JL (1992) Mass-transfer and kinetic aspects in continuous bioreactors using Rhodospirillum rubrum. Appl Biochem Biotechnol 34-35:613624

Cox HH (1995) Styrene Removal from waste gas by the fungus Exophiala jeanselmei in a biofilter. $\mathrm{PhD}$ Thesis, Rijksuniversiteit Groningen, the Netherlands

Cox HH, Nguyen TT, Deshusses MA (2000) Toluene degradation in the recycle liquid of biotrickling filters for air pollution control. Appl Microbiol Biotechnol 54:133-137

Daugulis AJ, Amsden BG, Bochanysz J, Kayssi A (2003) Delivery of benzene to Alcaligenes xylosoxidans by solid polymers in a two-phase partitioning bioreactor. Biotechnol Lett 25:1203-1207

Davison CT, Daugulis AJ (2003) The treatment of gaseous benzene by two-phase partitioning bioreactors: a high performance alternative to the use of biofilters. Appl Microbiol Biotechnol 62:297301

Davison BH, Barton JW, Klasson KT, Francisco AB (2000) Influence of high biomass concentrations on alkane solubilities. Biotechnol Bioeng 68:279-284

Delaloye MM, Stockar UV, Xiao-ping L (1991) The influence of viscosity on the liquid-phase mass transfer resistance in packed columns. Chem Eng J 47:51-61

Devinney JS, Ramesh J (2005) A phenomenological review of biofilter models. Chem Eng J 113:187-196

Déziel E, Corneau Y, Villemur R (1999) Two-liquid-phase bioreactors for enhanced degradation of hydrophobic/toxic compounds. Biodegradation 10:219-233

Djeribi R, Dezenclos T, Pauss A, Lebeault JM (2005) Removal of styrene from waste gas using a biological trickling filter. Eng Life Sci 5:450-457

Dorado AD, Rodríguez G, Ribera G, Bonsfills A, Gabriel D, Lafuente J, Gamisans X (2009) Evaluation of mass transfer coefficients in biotrickling filters: experimental determination and comparison to correlations. Chem Eng Technol 32:1941-1950

Ebrahimi S, Kleerebezem R, Kreutzer MT, Kapteijn F, Moulijn JA, Heijen JJ, van Loosdrecht MCM (2005a) Potential application of monlith packed columns as bioreactors, control of biofilm formation. Biotechnol Bioeng 93:238-245

Ebrahimi S, Picioreanu C, Xavier JB, Kleerebezem R, Kreutzer MT, Kapteijn F, Moulijn JM, van Loosdrecht MCM (2005b) Biofilm growth pattern in honeycomb monolith packings: effect of shear rate and substrate transport limitations. Catal Today 105:448-454

Estrada JM, Kraakman NJR, Muñoz R, Lebrero R (2011) A comparative analysis of odour treatment technologies in wastewater treatment plants. Environ Sci Technol 45:1100-1106 
Fazaelipoor MH, Shojaosadati SA (2002) The effect of silicone oil on biofiltration of hydrophobic compounds. Environ Progr 21:221224

Galindo E, Pacek AW, Nienow AW (2000) Study of drop and bubble sizes in a simulated mycelial fermentation broth of up to four phases. Biotechnol Bioeng 69:213-221

Gomez-Diaz D, Navaza J (2003) Mass transfer in a flat gas/liquid interface using non-Newtonian media. Chem Eng Technol 26:1068-1073

Goncalves JJ, Govind R (2009) Enhanced biofiltration using cell attachment promotors. Environ Sci Technol 43:1049-1054

Groenestijn JW, van Kraakman NJR (2005) Recent developments in biological waste gas purification in Europe. Chem Eng J 113:8591

Groenestijn JW, van Lake ME (1999) Elimination of alkanes from offgases using biotrickling filters containing two liquid phases. Environ Prog 18:151-155

Groenestijn JW, van Heiningen WN, van Kraakman NJR (2001) Biofilters based on the action of fungi. Water Sci Technol 44:227-232

Hamme JD, van Sing A, Ward OP (2003) Recent advances in petroleum microbiology. Microbiol Mol Biol Rev 67:503549

Han B, Wu H, Gou Z, Xing XH, Jiang H, Chen Y, Li X, Murrel JC (2009) Paraffin oil as a "methane vector" for rapid and high cell density cultivation of Methylosinus trichosporium OB3b. Appl Microbiol Biotechnol 83:669-677

Harms H, Bosma TNP (1997) Mass transfer limitation of microbial growth and pollutant degradation. J Ind Microbiol Biotechnol 18:97-105

Hernandez M, Quijano G, Thalasso F, Daugulis AJ, Villaverde S, Muñoz R (2010) A comparative study of solid and liquid non-aqueous phases for the degradation of hexane in twophase partitioning bioreactors. Biotechnol Bioeng 106:731740

Heymes F, Manno DP, Charbit F, Fanlo JL, Moulin P (2006) Hydrodynamics and mass transfer in a packed column: case of toluene absorption with a viscous absorbent. Chem Eng Sci 61:5094-5106

Hoffmann A, Mackowiak JF, Gorak A, Hass M, Loning JM, Runowski T, Hallenberger K (2007) Standardization of mass transfer measurements: a basis for the description of absorption processes. Chem Eng Res Des 85:40-49

Jin Y, Guo L, Veiga MC, Kennes C (2007) Fungal biofiltration of $\alpha$-pinene: the effect of temperature, relative humidity and transient loads. Biotechnol Bioeng 96:433-443

Joosten GEH, Danckwerts PV (1973) Chemical reaction and effective interfacial areas in gas adsorption. Chem Eng Sci 28:453-461

Kennes C, Veiga MC (eds) (2001) Bioreactors for waste gas treatment. Kluwer Acadamic Publicers, Dordrecht

Kim S, Deshusses MA (2008) Determination of mass transfer coefficients for packing materials used in biofilters and biotrickling filters for air pollution control. 1. Experimental results. Chem Eng Sci 63:841-855

Koch AL (1990) Diffusion - the crucial process in many aspects of th biology of bacteria. In: Marcshall KC (ed) Adv Microbiol Ecol 11. Plenum Press, New York, pp 37-70

Kraakman NJR, Groenestijn JW, van Koers B et al. (1997) Styrene removal using a new type of bioreactor with fungi. Proceedings of an international symposium on Biological Waste Gas Cleaning. WL Prins and J van Ham (eds.), pp. 225-232, 28-29 April, Maastricht, The Netherlands

Kreutzer MT, Kapteijn F, Moulijn JA, Ebrahimi S, Kleerebezem R, van Loosdrecht MCM (2005a) Monoliths as biocatalytic reactors: smart gas-liquid contacting for process intensification. Ind Eng Chem Res 44:9646-9652
Kreutzer MT, Kapteijn F, Moulijn JA, Heiszwolf JJ (2005b) Multiphase monolith reactors: chemical reaction engineering of segmented flow in microchannels. Chem Eng Sci 60:58955916

Kreutzer MT, Kapteijn F, Moulijn JA (2006) Shouldn't catalysts shape up? Structured reactors in general and gas-liquid monolith reactors in particular. Catal Today 111:111-118

Lebrero R, Rodriguez E, Martin M, Garcia-Encina PA, Munoz R (2010) $\mathrm{H}_{2} \mathrm{~S}$ and VOCs abatement robustness in biofilters and air diffusion bioreactors: a comparative study. Water Res 44:39052914

Lewis WK, Whitman WG (1924) Principles of gas absorption. Ind Eng Chem 16:1215-1220

Linek V, Vacek V (1981) Chemical engineering use of catalyzed sulfite oxidation kinetics for the determination of masstransfer characteristics of gas-liquid contactors. Chem Eng Sci 36:1747-1768

Linek V, Moucha T, Rejl JF (1984) Effective interfacial area and liquid side mass transfer coefficients in adsorption columns packed with hydrophillised and untreated plastic packings. Chem Eng Res Des 62:13-21

Linek V, Sinkule J, Brekke K (1995) A critical evaluation of the use of absorption mass transfer data for the design of packed distillation columns. Chem Eng Res Des 73:398-405

Linek V, Moucha T, Rejl JF (2001) Hydraulic and mass transfer characteristics of packings for adsorption and sterilization columns, Rauschert-Metall-Sattel-Rings. Chem Eng Res Des 79:725-732

Littlejohns JV, Daugulis AJ (2009) A two-phase partitioning airlift bioreactor for the treatment of BTEX contaminated gases. Biotechnol Bioeng 103:1077-1086

Liu H, Vandu CO, Krishna R (2005) Hydrodynamics of Taylor flow in vertical capillaries: flow regimes, bubble rise velocity, liquid slug length, and pressure drop. Ind Eng Chem Res 44:4884-4897

McLeod CT, Daugulis AJ (2005) Interfacial effects in a two-phase partitioning bioreactor: degradation of polycyclic aromatic hydrocarbons (PAHs) by an hydrophobic Mycobacterium. Proc Biochem 40:1799-1805

Miller MJ, Allen DG (2005) Biodegradation of $\alpha$-pinene in model biofilms in biofilters. Environ Sci Technol 39:5856-5863

Montes M, Rene E, Veiga MC, Kennes C (2009) Two liquid phase thermophilic and mesophilic biotrickling filters for the biodegradation of $\alpha$-pinene. Biores Technol 101:9493-9499

Montes M, Daugulis AJ, Veiga MC, Kennes C (2011) Characterization of absorbent polymers for the removal of volatile hydrophobic pollutants from air. J Chem Technol Biotechnol 86:47-53

Muñoz R, Arriaga S, Hernandez S, Guieysse B, Revah S (2006) Enhanced hexane biodegradation in a two phase partitioning bioreactor: overcoming pollutant transport limitations. Proc Biochem 41:1614-1619

Muñoz R, Villaverde S, Guieysse B, Revah S (2007) Two-phase partitioning bioreactors for treatment of volatile organic compounds. Biotechnol Adv 25:410-422

Nielsen DR, Daugulis AJ, Mclellan PJ (2005) Transient performance of a two-phase partitioning bioscrubber treating a benzenecontaminated gas stream. Environ Sci Technol 39:8971-8977

Nijhuis TA, Beers AEW, Vergunst T, Hoek I, Kapteijn F, Moulijn JA (2002) Preparation of monolithic catalysts. Catal Rev Sci Eng 43:345-380

Paca J, Halecky M, Kozliac E (2009) Styrene biofiltration using two packing materials with different adsorption properties. Environ Eng Sci 26:195-208

Painmanakul P, Loubiere K, Roustan M, Hebrard G, Mietton-Peuchot M, Gilles H (2005) Effect of surfactants on liquid-side mass transfer coefficients. Chem Eng Sci 60:6480-6491 
Popat SC, Deshusses MA (2010) Analysis of the rate-limiting step of an anaerobic biotrickling filter removing TCE vapors. Proc Biochem 45:549-555

Prenafeta-Boldu FX, Illa J, Groenestijn JW, van Flotats X (2008) Influence of synthetic packing materials on the gas dispersion and biodegradation kinetics in fungal air biofilters. Appl Microbiol Biotechnol 79:319-327

Quijano G, Hernandez M, Thalasso F, Muñoz R, Villaverde S (2009a) Two-phase partitioning bioreactors in environmental biotechnology. App Microbiol Biotechnol 84:829-846

Quijano G, Revah S, Gutierrez-Rojas M, Flores-Cotera L, Thalasso F (2009b) Oxygen transfer in three-phase airlift and stirred reactors using silicone oil as transfer vector. Proc Biochem 44:619 624

Quijano G, Hernandez M, Villaverde S, Thalasso F, Muñoz R (2010a) A step-forward in the characterization and potential applications of solid and liquid oxygen transfer vectors. Appl Microbiol Biotechnol 85:543-551

Quijano G, Rocha-Rios J, Hernandez M, Villaverde S, Revah S, Muñoz R, Thalasso F (2010b) Determining the effect of solid and liquid vectors on the gaseous interfacial area and oxygen transfer rates in two-phase partitioning bioreactors. J Hazard Mater 175:1085-1089

Ramirez-Lopez EM, Montillet A, Comiti J, Le Cloirec P (2000) Biofiltration of volatile organic compounds - application to air treatment. Water Sci Technol 12:183-190

Ratledge C (1977) Fermentation substrates. Ann Rep Ferment Proc $1: 49-71$

Rejl JF, Linek V, Moucha T, Valenz L (2009) Methods standardization in the measurement of mass-transfer characteristics in packed absorption columns. Chem Eng Res Des 87:695-704

Rocha-Rios J, Bordel S, Hernandez S, Revah S (2009) Methane degradation in two-phase partition bioreactors. Chem Eng J 152:289-292

Rocha-Rios J, Muñoz R, Revah S (2010) Effect of silicone oil fraction and stirring rate on methane degradation in a stirred tank reactor. J Chem Technol Biotechnol 85:314-319

Rocha-Rios J, Quijano G, Thalasso F, Revah S, Muñoz R (2011a) Methane biodegradation in a two-phase partition internal loop airlift reactor with gas recirculation. J Chem Technol Biotechnol 86:353360

Rocha-Rios J, Kraakman NJR, Revah S, Kleerebezem R, Kreutzer M, van Loosdrecht MCM (2011b) A capillary bioreactor to increase methane transfer and consumption. (in press)

Rosenberg M (1991) Basic and applied aspects of microbial adhesion at the hydrocarbon-water interface. Crit Rev Microbiol 18:15-173
Shao N, Gavriilidis A, Angeli P (2010) Mass transfer during Taylor flow in micro channels with and without chemical reaction. Chem Eng J 160:730-880

Shareefden Z, Singh A (eds) (2005) Biotechnology for odour and air pollution control. Springer-Verlag, Heidelberg

Spigno G, Pagella C, Fumi MD, Molteni R, De Faveri DM (2003) VOCs removal from waste gases: gas phase bioreactor for the abatement of hexane by Aspergillus niger. Chem Eng Sci 58:739-746

Stankiewicz A (2001) Process intensification in in-line monolithic reactor. Chem Eng Sci 56:359-364

Suresh S, Srivastava VC, Mishra IM (2009) Techniques for oxygen transfer measurement in bioreactors: a review. J Chem Technol Biotechnol 84:1091-1103

Vergara-Fernandez A, Haaren B, van Revah S (2006) Phase partition of gaseous hexane and surface hydrophobicity of Fusarium solani when grown in liquid and solid media with hexanol and hexane. Biotechnol Lett 28:2011-2017

Wang GQ, Yuan XG, Yu KT (2005) Review of mass-transfer correlations for packed columns. Ind Eng Chem Res 44:87158729

Warneck P (1988) Chemistry of the natural atmosphere. Academic Press, San Diego

Woertz JR, Kinney KA, Szaniszlo PJ (2001) A fungal vapor-phase bioreactor for the removal of nitrous oxide from waste gas streams. J Air Waste Manag Assoc 51:895-902

Woertz JR, Heiningen WN, van Eekert MH, van Kraakman NJR, Kinney KA, Groenestijn JW (2002a) Dynamic bioreactor operation: effects of packing material and mite predation on toluene removal from off-gas. Appl Microbiol Biotechnol 58:690-694

Woertz JR, Kinney KA, Heiningen WN, van Eekert MH, van Kraakman NJR, Groenestijn JW (2002b) Mite growth on fungus under various environmental conditions and its potential application in biofilters. Exp Appl Acarol 27:265-276

Wosten HAB (2001) Hydrophobins: multipurpose proteins. Annu Rev Microbiol 55:625-646

Wosten HAB, Wetter MA, van Lugones LG, der Mei HC, van Bussher HJ, Wessels JGH (1999) How fungus escapes the water to grow into the air. Curr Biol 9:85-88

Wubbolts MG, Favre-Bulle O, Witholt B (1996) Biosynthesis of synthons in two-liquid-phase media. Biotechnol Bioeng 52:301308

Yeom SH, Daugulis AJ (2001) Development of a novel bioreactor system for treatment of gaseous benzene. Biotechnol Bioeng $72: 156-164$ 